\title{
Significance of Coronary Artery to Pulmonary Artery Fistulae in Takayasu Arteritis
}

\author{
George Joseph ${ }^{1}$ \\ ${ }^{1}$ Department of Cardiology, Christian Medical College, Vellore, \\ Tamil Nadu, India \\ Indian J Cardiovasc Dis Women-WINCARS 2018;3:2-3
}

In this issue of Indian Journal of Cardiovascular Disease in Women, Moode et $\mathrm{al}^{1}$ present the clinical and imaging features of a series of patients with Takayasu arteritis (TA), with special focus on coronary artery involvement and the presence of coronary artery-pulmonary artery fistulae.

Takayasu arteritis was originally classified by Ueno et al ${ }^{2}$ in 1967 into three main types. Type IV was added by Lupi et $\mathrm{al}^{3}$ when there was associated pulmonary artery involvement, and type $\mathrm{V}$ was added by Panja et $\mathrm{al}^{4}$ when there was associated coronary artery involvement. However, the classification by Ueno et al and the later additions have been largely supplanted by the system proposed by Numano's group ${ }^{5,6}$ in which there are five main types of TA (type II being divided into subtypes $a$ and $b$ ) and in which associated pulmonary and coronary artery involvements are indicated as $\mathrm{P}(+)$ and $\mathrm{C}(+)$, respectively.

\section{Angiographic Classification of Takayasu Arteritis (Numano) ${ }^{5,6}$}

Type I-Only branches of aortic arch involved.

Type IIa-Ascending aorta and/or aortic arch involved +/branches of aortic arch.

Type IIb-Descending thoracic aorta +/- type II a distribution. Abdominal aorta not involved.

Type III-Descending thoracic aorta and abdominal aorta and/or renal arteries involved.

Type IV-Abdominal aorta and/or renal arteries involved.

Type V-Generalized type with combined features of the other types.

Note: Involvement of the coronary or pulmonary arteries is indicated as $\mathrm{C}(+)$ and $\mathrm{P}(+)$, respectively.

Coronary involvement in TA has varied from 8 to $38 \%$ in various series and most commonly affects the ostial and proximal segments of the coronary arteries. ${ }^{7-9}$ Computed tomographic (CT) angiography reveals coronary artery involvement in a higher proportion of TA patients (44-53\%). ${ }^{10,11}$ At Christian Medical College, Vellore, 91 (18.0\%) of 505 TA patients who underwent conventional coronary angiography over a 23-year period had evidence of coronary artery involvement; presence of coronary artery-pulmonary artery fistulae was not classified as a coronary artery abnormality in this series.

Demonstration of systemic artery-pulmonary artery communications in TA in the absence of other causes of a shunt is strongly suggestive of pulmonary artery involvement. ${ }^{12}$ Such communications may arise from internal mammary, bronchial, lateral thoracic, intercostal, and coronary arteries. ${ }^{12-17}$ Development of these communications is considered to be secondary to pulmonary involvement with reduced perfusion pressure in the affected part of the lung. ${ }^{18}$ Pulmonary angiography in the two patients presented in the current report could have shed more light on this aspect. In any case, presence of coronary artery-pulmonary artery fistulae in TA is reflective of pulmonary involvement and is not a primary pathology of the coronary arteries; therefore, rather than classifying such fistulae as a subtype of coronary artery involvement in TA, it may be more appropriate to consider this as pulmonary involvement with systemic collaterals and designate it $\mathrm{P}(+)$ with systemic collaterals. Endo et al, ${ }^{7}$ however, classified the presence of coronary artery-pulmonary artery fistulae as a coronary artery abnormality of $\mathrm{TA}$, underscoring the fact that there is no uniformity in the nomenclature used by different workers.

\section{Conflict of Interest}

None.

\section{References}

1 Moode S, Malayathi S, Maddury J, Nemani L. Does Type 5 of Takayasu's Arteritis Require Subclassification? Ind J Car Dis Wom 2018;3(1):23-26

2 Ueno A, Awane Y, Wakabayashi A, Shimizu K. Successfully operated obliterative brachiocephalic arteritis (Takayasu) associated with the elongated coarctation. Jpn Heart J 1967;8 (5):538-544

3 Lupi E, Sánchez G, Horwitz S, Gutierrez E. Pulmonary artery involvement in Takayasu's arteritis. Chest 1975;67(1):69-74
Address for correspondence George Joseph, MD, DM, FCSI, Department of Cardiology, Christian Medical College, Vellore 632004, Tamil Nadu, India (e-mail: joseph59@gmail.com).
DOI https://doi.org/ 10.1055/s-0038-1667389.
Copyright $\odot 2018$ Women in Cardiology and Related Sciences
License terms

() (1) $\Theta \circledast$ 
4 Panja M, Sarkar C, Panjan W, Kumar S. Non-specific aorto-arteritis: classification and clinical manifestations. In: Panjan M, ed. Non-specific Aorto-arteritis. Kolkata, India: Marksman Media Services; 2001:41-50

5 Hata A, Noda M, Moriwaki R, Numano F. Angiographic findings of Takayasu arteritis: new classification. Int J Cardiol 1996;54(Suppl):S155-S163

6 Moriwaki R, Noda M, Yajima M, Sharma BK, Numano F. Clinical manifestations of Takayasu arteritis in India and Japannew classification of angiographic findings. Angiology 1997;48(5):369-379

7 Endo M, Tomizawa Y, Nishida $\mathrm{H}$, et al. Angiographic findings and surgical treatments of coronary artery involvement in Takayasu arteritis. J Thorac Cardiovasc Surg 2003;125(3):570-577

8 Panja M, Sarkar C, Kar AK, et al. Coronary artery lesions in Takayasu's arteritis-clinical and angiographic study. J Assoc Physicians India 1998;46(8):678-681

9 Sun T, Zhang H, Ma W, et al. Coronary artery involvement in Takayasu arteritis in 45 Chinese patients. J Rheumatol 2013;40(4):493-497

10 Soto ME, Meléndez-Ramírez G, Kimura-Hayama E, et al. Coronary CT angiography in Takayasu arteritis. JACC Cardiovasc Imaging 2011;4(9):958-966

11 Kang EJ, Kim SM, Choe YH, Lee GY, Lee KN, Kim DK. Takayasu arteritis: assessment of coronary arterial abnormalities with 128-section dual-source CT angiography of the coronary arteries and aorta. Radiology 2014;270(1):74-81

12 Ishikawa T. Systemic artery-pulmonary artery communication in Takayasu's arteritis. AJR Am J Roentgenol 1977;128(3):389-393

13 He NS, Liu F, Wu EH, et al. Pulmonary artery involvement in aorto-arteritis. An analysis of DSA. Chin Med J (Engl) 1990;103(8):666-672

14 Horimoto M, Igarashi K, Aoi K, Okamoto K, Takenaka T. Unilateral diffuse pulmonary artery involvement in Takayasu's arteritis associated with coronary-pulmonary artery fistula and bronchial-pulmonary artery fistula: a case report. Angiology 1991;42(1):73-80

15 Sharma S, Talwar KK, Rajani M. Coronary artery to pulmonary artery collaterals in nonspecific aortoarteritis involving the pulmonary arteries. Cardiovasc Intervent Radiol 1993;16(2):111-113

16 Ercan E, Tengiz I, Yakut N, Gurbuz A, Bozdemir H, Bozdemir G Takayasu's arteritis with multiple fistulas from three coronary arteries to lung paranchima. Int J Cardiol 2003;88(2-3):319-320

17 Karabay KO, Altuntas E, Uysal E, Ozkara A, Aytekin V. Takayasu arteritis with multiple coronary artery fistulas to bronchial arteries. Int J Angiol 2016;25(5):e1-e3

18 Liebow AA, Hales MR, Bloomer WE. Relation of bronchial to pulmonary vascular tree. In: Adams WR. Veith I, eds. Pulmonary Circulation. New York, NY: Grune \& Stratton; 1958:79-98 